\title{
Sequential bcl-2 and c-myc Oncogene Rearrangements Associated with the Clinical Transformation of Non-Hodgkin's Lymphoma
}

\author{
J. Thomas Lee, Donald J. Innes, Jr., and Michael E. Williams \\ Departments of Internal Medicine and Pathology, and the Diagnostic Molecular Genetics Laboratory, \\ University of Virginia Health Sciences Center, Charlottesville, Virginia 22908
}

\begin{abstract}
We report a case of untreated non-Hodgkin's lymphoma with histologic progression over 1 yr from a low-grade, small cleaved follicular center cell lymphoma to a high-grade, small noncleaved follicular center cell lymphoma. Both lymphomas had identical immunoglobulin (Ig) heavy-chain joining gene $\left(J_{H}\right)$, kappa light-chain joining gene, and bcl-2 gene rearrangements, indicating the clonal identity of the two tumors. The Ig heavy chain locus on one chromosome 14 was involved in an initial $t(14 ; 18)$ translocation as shown by comigrating $J_{H}$ and bcl-2 rearrangements. However, the oncogene c-myc was in the germline configuration in the initial lymphoma but had one allele rearranged near the $3^{\prime}$ end of exon $I$ in the high-grade tumor; DNA sequence analysis was consistent with a chromosomal breakpoint at that site. The presence of the c-myc rearrangement in the high-grade tumor suggests a role for c-myc in the clonal evolution of the low-grade tumor into a more aggressive lymphoma. The coexistence of both bcl-2 gene and c-myc oncogene rearrangements in the same tumor is unusual, with only a few cases reported. Furthermore, this case is unique in the direct demonstration of the histologic and clinical progression of a human lymphoma associated with the sequential rearrangement of the bcl-2 gene and the c-myc oncogene.
\end{abstract}

\section{Introduction}

The clinical and histologic transformation of malignant lymphoma from a low- to a high-grade tumor is well described (1, 2). In some cases the aggressive tumor has been shown to arise from its indolent predecessor by immunophenotypic, cytogenetic, or gene rearrangement studies (2-5). However, the critical molecular events associated with this histologic and clinical transformation remain unknown. Recent findings implicate the activation of certain oncogenes in lymphoma pathogenesis, often in association with specific chromosomal translocations $(6,7)$. The translocation $t(14 ; 18)$ is found in up to $85 \%$ of follicular lymphomas and results in rearrangement of the putative oncogene bcl-2 (8-11). This rearrangement also occurs less commonly in some diffuse high-grade lymphomas

Presented in part at the 25th Annual Meeting of the American Society of Clinical Oncology, 21 May 1989, San Francisco, CA (Abstract No. 992) and in abstract form (1989. J. Clin. Oncol. 8:254a).

Address reprint requests to Dr. Michael E. Williams, Department of Internal Medicine, Box 502, University of Virginia Health Sciences Center, Charlottesville, VA 22908.

Received for publication 3 April 1989 and in revised form 13 July 1989.

J. Clin. Invest.

(c) The American Society for Clinical Investigation, Inc. $0021-9738 / 89 / 11 / 1454 / 06 \$ 2.00$

Volume 84, November 1989, 1454-1459
(11-13). Small noncleaved follicular center cell malignant lymphomas (Burkitt's type) typically have rearrangement of the c-myc oncogene, usually associated with a $t(8 ; 14)$ translocation (6). A composite lymphoma has been reported in which both the low- and high-grade components had an identical bcl-2 rearrangement, but only the high grade component had a rearrangement of the $c-m y c$ oncogene (14). This suggests that the low-grade lymphoma with a bcl- 2 rearrangement acquired a second translocation resulting in the activation of c-myc, contributing to the transformation to a high-grade lymphoma.

We report a patient with the sequential transformation of a small cleaved follicular center cell lymphoma into a small noncleaved follicular center cell lymphoma, and provide evidence for clonal identity by both immunophenotype markers and gene rearrangement analysis. Both lymphomas carry the same bcl-2 gene rearrangement; in addition, the small noncleaved follicular center cell lymphoma acquired a rearrangement of the c-myc oncogene, suggesting an important role for c-myc in the progression of this tumor.

\section{Methods}

Case report. A 50-yr-old black woman developed a 2-cm skin nodule above her right eye in May 1986. Physical examination showed no peripheral lymphadenopathy or other skin lesions. A biopsy of the nodule showed small cleaved follicular center cell malignant lymphoma (Fig. 1). A bone marrow biopsy was also involved with small cleaved follicular center cell lymphoma. A computed tomographic scan of the abdomen showed mesenteric and retroperitoneal adenopathy with the lymph nodes measuring up to $3 \mathrm{~cm}$. She had no systemic symptoms and was treated only with radiation therapy to the periorbital skin mass with complete resolution of the lesion.

1 yr after initial presentation she developed generalized lymphadenopathy with a rapidly enlarging left axillary lymph node, night sweats and fevers, without the presence of skin lesions. Her LDH increased from 539 to 4,565 U/liter (normal 230-450). Biopsy of a 5-cm axillary lymph node showed malignant lymphoma, small noncleaved follicular center cell (Fig. 1).

She received five cycles of cyclophosphamide, doxorubicin, vincristine, and prednisone (CHOP) chemotherapy with a complete resolution of her symptoms and adenopathy. She remains in clinical complete remission 12 mo since completing chemotherapy.

Morphologic and immunophenotypic studies. Fresh biopsy tissue was immediately fixed in $10 \%$ formalin for paraffin and plastic embedding. $4-\mu \mathrm{m}$-thick sections were cut and stained with hematoxylin and eosin. Additional sections were processed for immunoperoxidase studies using an avidin-biotin-complex and 3,3'-diaminobenzidine (DAB) substrate as previously described in detail (15).

Primary antibodies to kappa and lambda light chains (Tago, Inc., Burlingame, CA) and to immunoglobulin heavy chains IgM, IgD, IgA, IgG, and IgE (DAKO Corp., Santa Barbara, CA) were used. Sections stained with nonrelevant antibodies and with buffer substitution for primary antibody served as negative controls. Positive control sections of normal adenoid tissue were stained with each of the study antibodies.

DNA studies. Tissue samples from the skin biopsy and lymph node biopsy were snap-frozen in liquid nitrogen vapors and stored at 
$-70^{\circ} \mathrm{C}$. Southern blot analysis was performed using standard procedures. 5- $\mu \mathrm{g}$ aliquots of purified DNA were digested under recommended conditions with a panel of restriction endonucleases (Bethesda Research Laboratories, Bethesda, MD). The resulting DNA fragments were size-separated in $0.7 \%$ agarose gels and transferred onto nylon membranes (Zeta Probe; Bio-Rad Laboratories, Richmond, CA) using the alkaline transfer modification of the method of Southern $(16,17)$. The blots were serially hybridized with ${ }^{32} \mathrm{P}$-labeled probes from the Ig heavy-chain joining genes $\left(\mathrm{J}_{\mathrm{H}}\right)$, the kappa light-chain joining genes $\left(J_{K}\right)$, the $T$ cell receptor gamma chain joining genes and the $T$ cell receptor beta chain constant gene (Oncor, Gaithersburg, MD). Other probes included a $2.5-\mathrm{kb}$ Bam HI-Hind III probe for the Ig kappa light chain deleting element and a $1.5-\mathrm{kb}$ Hind III-Eco RI fragment from the bcl-2 gene at the chromosome 18q21 breakpoint of the $t(14 ; 18)$ translocation found in many follicular lymphomas $(10,18$; both kindly provided by Dr. Stanley Korsmeyer, Washington University School of Medicine, St. Louis), a 1.8-kb Cla I-Eco RI fragment containing the third exon of human c-myc and a 3.0-kb Hind III-Xba I c-myc exon I fragment (subcloned from human c-myc pMC41, kindly provided by Dr. Takis Papas, National Cancer Institute, Bethesda), a 0.6-kb human mu constant gene cDNA (kindly provided by Dr. Leroy Hood, California Institute of Technology, Pasadena), a 6.6-kb Bam HI-Hind III probe from the human $\mathrm{IgG}_{4}$ locus and a 2.6-kb Bam $\mathrm{HI}$ probe from the human IgE constant $\left(\mathrm{E}_{\mathrm{C}}\right)$ gene $(19,20$; both kindly provided by $\mathrm{Dr}$ Philip Leder, Harvard Medical School, Boston). All probes were gel purified from their plasmid vectors before radiolabeling with ${ }^{32} \mathrm{P}-\mathrm{nu}-$ cleotides by the random primed method using a reagent kit (21; Boehringer Mannheim Biochemicals, Indianapolis, IN). Hybridization, autoradiography, and rehybridization were performed as previously reported (22). Gene rearrangement was determined by the presence of nongermline bands on autoradiograms as compared to placental control DNA.
DNA sequence analysis to further characterize the rearranged c-myc gene was performed by constructing a Bam $\mathrm{HI}$ genomic library from high-grade tumor DNA in the Lambda Gem-ll bacteriophage cloning vector, a derivative of EMBL-3 (Promega Biotec, Madison, WI). The library was screened with the c-myc exon III probe; a Bam HI-Xba I fragment from a positive clone was subcloned into M13 sequencing vectors using MP18 and MP19 primers. The DNA sequence of the 368-bp Bam HI-Xba I fragment containing the breakpoint was determined by the dideoxynucleotide chain-termination method (23; SEQUENASE; U. S. Biochemical Corp., Cleveland, OH).

\section{Results}

Histology and immunopathology. $\mathrm{H}$ and $\mathrm{E}$ histologic sections (Fig. 1) were examined and classified using the criteria and terminology of the Lukes-Collins system $(24,25)$. The small cleaved follicular center cell lymphoma has been designated as low grade and the small noncleaved follicular center cell lymphoma as high grade based on prognostic characteristics of these neoplasms (26). Immunologic studies identified both the low- and high-grade lymphomas as B cell lesions monoclonal for Ig kappa light chain. Immunoglobulin heavy chains were not detected in tumor cells from either the low- or high-grade lesions.

DNA studies. The results of Southern blot analysis with the $\mathbf{J}_{\mathrm{H}}$ and bcl-2 probes are shown in Fig. 2. DNA from the lowgrade tumor showed a single rearranged $\mathrm{J}_{\mathbf{H}}$ band that comigrated with the single rearranged bcl- 2 band, consistent with the presence of the translocation $t(14 ; 18)(10)$. These same rearranged $J_{H}$ and bcl-2 bands are present in the high-grade
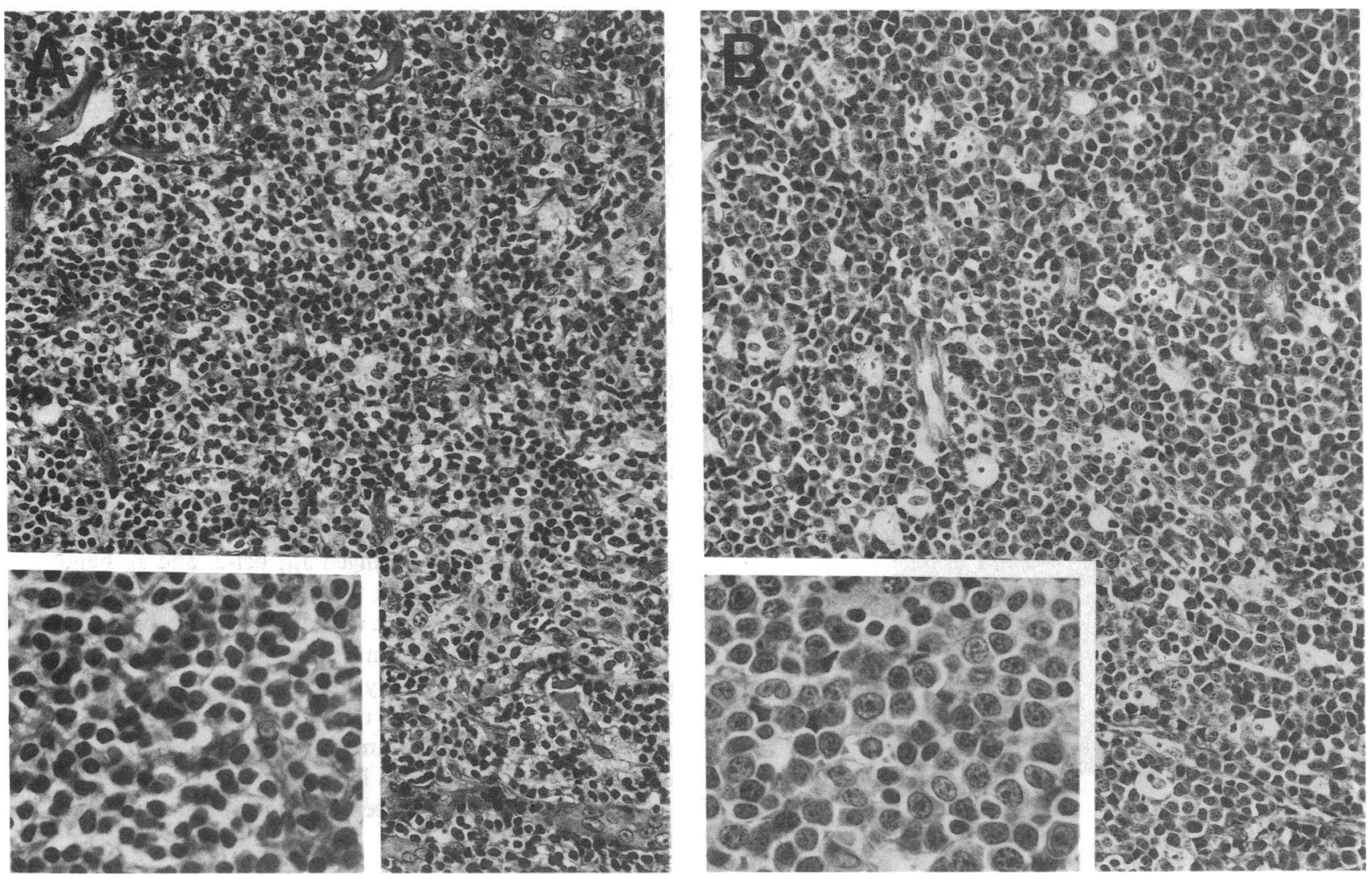

Figure 1. Photomicrographs of the initial periorbital skin lesion showing small cleaved cell malignant lymphoma $(A)$ and the subsequent axillary lymph node biopsy showing small noncleaved cell malignant lymphoma $(B)$. Hematoxylin and eosin, $\times 250$; insets, $\times 500$. 


\section{Low Grade}

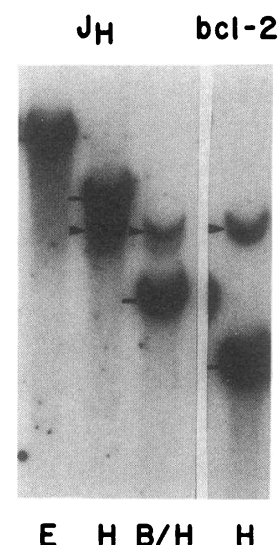

High Grade

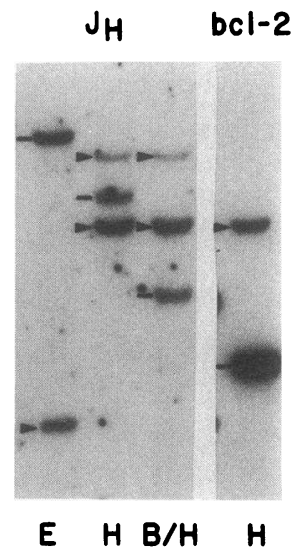

Figure 2. Southern blot autoradiogram from low- and high-grade lymphomas using immunoglobulin heavy chain joining gene $\left(\mathrm{J}_{\mathrm{H}}\right)$ and bcl-2 gene probes. The high-grade tumor carries the same $J_{H}$ and bcl-2 rearrangement (arrows) as does the low-grade tumor; an additional $\mathbf{J}_{\mathrm{H}}$ rearrangement is present in the high-grade tumor. Germline band positions are indicated by dashes. Restriction enzymes included Eco R1 $(E)$, Hind III $(H)$, and a combination of Bam HI and Hind III $(B / H)$.

tumor, indicating the derivation of this tumor from the lowgrade tumor clone. A second $\mathrm{J}_{\mathrm{H}}$ band is present in the highgrade tumor, indicating rearrangement of the heavy-chain allele not involved by $t(14 ; 18)$. Analysis with the $J_{K}$ probe showed a single identical rearranged band in each tumor, again demonstrating their derivation from the same clone. The kappa deleting element gene was in germline configuration in both tumors, as were the $T$ cell receptor gamma and beta chain genes (data not shown).

Hybridization analysis with the c-myc exon III probe showed the acquisition of a c-myc rearrangement in the highgrade tumor (Fig. 3). Restriction map analysis using the exon I

\section{Low Grade High Grade}

$$
c-m y c, \text { exon III }
$$

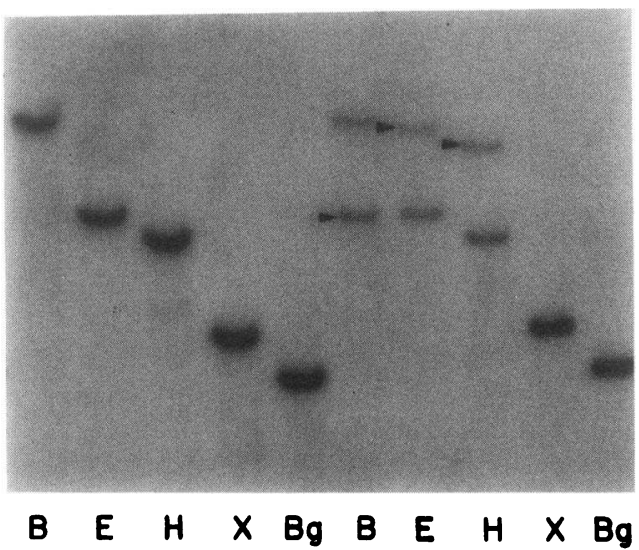

Figure 3. Southern blot autoradiogram using the c-myc exon III probe, showing rearrangements (arrows) in the high-grade tumor. Restriction enzymes include Bam HI $(B)$, Eco R1 $(E)$, Hind III $(H)$, $\mathrm{Xba}$ I $(X)$, and Bgl II $(B g)$. probe with Pvu II and Sac I restriction enzymes in addition to those enzymes shown in Fig. 3 (data not shown) localizes the breakpoint of this rearrangement near the $3^{\prime}$ end of exon I (Fig. 4). Because c-myc translocations in high-grade B cell lymphomas frequently involve the Ig heavy chain genes on chromosome $14(6)$, restriction analysis of these loci was performed. The low-grade tumor showed a germline $\mathrm{mu} \mathrm{IgG}_{4}$, and $E_{C}$ heavy chain gene configuration, whereas the mu constant genes were deleted from the high-grade tumor DNA. It is possible that mu deletion(s) were present in the low-grade tumor as well but could not be detected due to the high percentage of nontumor cell DNA in that sample, as shown by the relatively faint rearranged versus germline bands with the $\mathrm{J}_{\mathrm{H}}$ and bcl-2 probes (Fig. 2). The lack of identifiable IgM, IgG, or $\mathrm{IgE}$ heavy chain rearrangement and lack of expression of any heavy chain class by immunophenotyping studies raises the possibility that the signal for kappa gene rearrangement occurred during the $t(14 ; 18)$ translocation, thus allowing kappa light chain expression in the low-grade tumor in the absence of detectable heavy chain expression. A rearranged band and multiple deletions were observed in the high-grade tumor with the $\mathrm{IgG}_{4}$ probe; an $\mathrm{E}_{\mathrm{C}}$ rearrangement was also noted in this tumor. The rearranged $\mathrm{E}_{\mathrm{C}}$ and c-myc exon III bands comigrated on both Eco RI and Hind III digests, suggesting their coexistence on the same DNA segment.

$D N A$ sequence analysis. To specifically locate the c-myc breakpoint, and to identify the apparent adjacent translocation sequence, a 368-bp Bam HI-Xba I subclone containing the $c-m y c$ breakpoint was sequenced (Fig. 5). Comparing this sequence to a previously published c-myc exon I and $5^{\prime}$ first intron sequence (27), a breakpoint was identified within an Sac I site $383 \mathrm{bp}$ downstream from exon I. The sequence contained $247 \mathrm{bp}$ of the first c-myc intron, from the Sac I to the $\mathrm{Xba}$ I sites. Unfortunately, only 121 bases from the upstream Bam HI site to the breakpoint were obtained from this clone; no clearly homologous human gene sequences were identified by a nucleic acid data base search (28; GenBank; Intelligenetics, Mountain View, CA).

\section{Discussion}

This patient demonstrated the clinical and histologic progression of a low-grade small cleaved cell lymphoma into a highgrade small noncleaved cell lymphoma over a 1-yr period of observation without systemic antitumor therapy. The most common type of transformation of low-grade lymphomas is to a diffuse large cell lymphoma; progression to a small noncleaved cell lymphoma is uncommon $(1,2)$. The high-grade tumor was shown to have evolved from the low-grade tumor by virtue of identical rearranged $J_{H}$, bcl-2, and $J_{K}$ bands on Southern blot analysis. Both tumors showed comigration of a rearranged $\mathrm{J}_{\mathrm{H}}$ band with the rearranged bcl-2 band consistent with a $t(14 ; 18)$ chromosomal translocation $(10)$. The high grade tumor had additionally acquired a rearrangement of the c-myc oncogene. Although rearrangement of the bcl-2 gene and c-myc oncogenes are among the most common genetic alterations in human B cell lymphomas, their coexistence in the same tumor clone has been reported only occasionally $(14$, 29, 30).

Rearrangement of the bcl-2 gene on chromosome 18 occurs in the majority of follicular non-Hodgkin's lymphomas, moving it adjacent to the Ig heavy chain locus on 


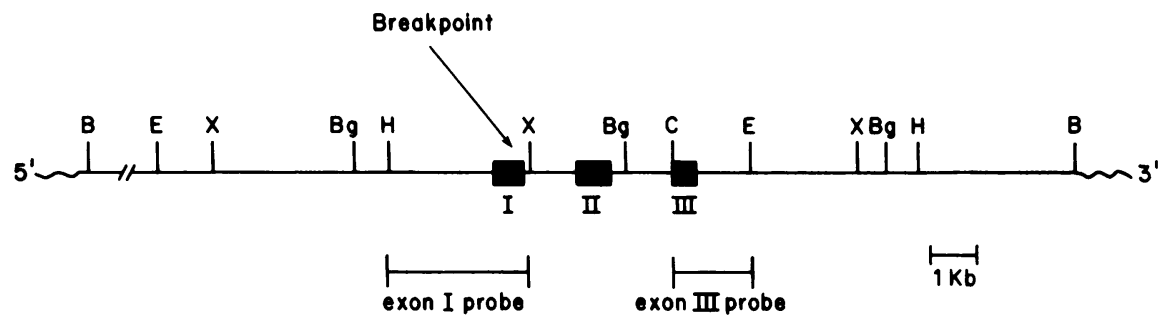

Figure 4. Partial restriction map of the human c-myc locus illustrating exons I, II, and III (black boxes) and the exon I and III probes utilized for analysis. The pattern of c-myc rearrangements (see Fig. 3 and text) places a breakpoint near the $3^{\prime}$ end of exon I. Restriction enzymes as indicated in Fig. 3; C, Cla I. chromosome 14. It also occurs in diffuse lymphomas but is less common $(12,13)$. The function of the protein product of this gene is unknown, but it is expressed in increased amounts in lymphomas that have the bcl-2 gene rearrangement (31-33).

Recent studies of patients with follicular lymphomas and the $t(14 ; 18)$ have shown a correlation between increasing clinical aggressiveness and higher histologic grade with the presence of additional chromosomal abnormalities $(4,34)$. Yunis et al. have proposed a model for the evolution of $t(14 ; 18)$ positive follicular lymphomas that involves the successive accumulation of certain recurrent genetic defects (4). In light of this proposal, it is of great interest that this patient acquired a rearrangement of $c-m y c$ in association with the transformation to a high-grade lymphoma, suggesting a pathogenic role for this oncogene in the tumor's progression. This is the first direct demonstration of successive oncogene rearrangements to be shown in sequential lymphoma tissue samples.

Translocations involving the c-myc locus on chromosome $8 \mathrm{q} 24$ are present in $45 \%$ of high-grade lymphomas and $10 \%$ of intermediate-grade lymphomas but are rare in low-grade lymphomas (7). The c-myc translocation is present in almost all cases of small noncleaved cell (endemic Burkitt's) lymphoma, with $90 \%$ of these having the $t(8 ; 14)$ translocation and the remainder having a $t(2 ; 8)$ or $t(8 ; 22)$ translocations. Each of these translocations results in the juxtaposition of c-myc and an Ig gene locus (chromosome 14, heavy chain; chromosome 2 , kappa light chain; chromosome 22, lambda light chain). In other small noncleaved cell lymphomas (sporadic [nonendemic] Burkitt's and Burkitt-like) c-myc is often translocated

\begin{tabular}{|c|c|}
\hline $\begin{array}{l}\text { ICCAGATGGCCAGGCTCATTCTGGGCCTITTCCCCACAATCCCCAGGCC } \\
\text { Bam H1 }\end{array}$ & 50 \\
\hline CAGGGCGGCTCCCAGGGCCCCCATTCCCCCACCAGAAGCTGTTGCTCAGC & 100 \\
\hline $\begin{array}{c}1 \mathrm{c}-\mathrm{myC} \\
\text { CACTATCATCAGGCTGGGCGC AGCTCCTTGGAGTAGGGACCGCATATCGC }\end{array}$ & 150 \\
\hline Sac I & \\
\hline $\begin{array}{l}\text { CTGTGTGAGCCAGATCGCTCCGCAGCCGCTGACTTGTCCC GTCTCCGGGA } \\
\text { (C) }\end{array}$ & 200 \\
\hline GGGCATTTAAATTTCGGCTCACCGCATTTCTGACAGCCGGAGACGGACAC & 250 \\
\hline $\begin{array}{l}\text { TGCGGCCGGTCCCGCCCGCCTGTCCCCGCGGCGATTCCAACCCGCCCTGA } \\
\text { (GC) }\end{array}$ & 300 \\
\hline TCCTTTTAAGAAGTTGGCATTTGGCTITTTAAAAAGCAATAATACAATTT & 350 \\
\hline AAACCTGGGTCTCTAGA & 368 \\
\hline Xbal & \\
\hline
\end{tabular}

Figure 5. DNA sequence of a 368-bp Bam Hl-Xba I fragment from the high-grade tumor DNA containing the chromosomal breakpoint (vertical arrow) in a Sac I site of the first c-myc intron. Variations from a previously reported first intron sequence are shown in parentheses (27). into one of the Ig heavy chain loci, apparently during an abortive attempt at heavy chain class switching (6). Detailed molecular analysis has shown that this translocation uses switch-homologous sequences flanking c-myc (6). The c-myc breakpoint in these cases usually occurs in the $5^{\prime}$ portion of $c-m y c$, disrupting exon $I$ or its immediate flanking sequences (6). Such translocations can therefore be detected using appropriate $c-m y c$ probes in Southern blot analysis. Unfortunately, in this case restriction analysis with multiple $\mathrm{Ig}$ and c-myc probes as well as DNA sequence analysis of the c-myc breakpoint have thus far failed to clearly establish whether a deletion or translocation event accounted for the observed c-myc rearrangement.

Mufti et al. first reported coexisting $t(8 ; 14)$ and $t(14 ; 18)$ translocations in a young man with acute lymphoblastic leukemia (35). Pegoraro et al. described a cell line from a patient with acute $B$ cell leukemia that had both a $t(14 ; 18)$ and $t(8 ; 14)$ chromosome translocation (29). This same group more recently reported a case of pre-B cell leukemia with a $t(8 ; 14)$ and a $t(14 ; 18)$ translocation in a patient previously diagnosed with a follicular, small cleaved non-Hodgkin's lymphoma (30). In both cases they postulated an initial $t(14 ; 18)$ translocation that resulted in a rearrangement of the bcl- 2 oncogene and clonal expansion of a low-grade tumor. A second translocation involving $\mathrm{t}(8 ; 14)$ may have then resulted in activation of the translocated c-myc oncogene, causing progression to a high grade malignancy. Recently, a clinical case supporting this sequence was described in a composite lymphoma in which a follicular small cleaved cell lymphoma had interfollicular areas infiltrated by TdT-positive lymphoblasts (14). After separation of the two cell types by a FACS it was shown that both components had identical $\mathbf{J}_{\mathbf{H}}$, kappa light chain, and bcl-2 rearrangements, but only the TdT-positive lymphoblasts had a c- $m y c$ rearrangement. Karyotype analysis from peripheral blood cells showed both $\mathrm{t}(14 ; 18)$ and $\mathrm{t}(8 ; 14)$ translocations.

Only a few other cases have been described in which there was sequential genetic analysis of a low-grade lymphoma transforming into a more aggressive lymphoma, and these have not shown the acquisition of a $t(8 ; 14)$ translocation or a c-myc rearrangement. In the study by Yunis et al. of 71 patients with a $t(14 ; 18)$ translocation, 4 patients who had minor subclones by karyotype analysis underwent histologic progression with the minor clones becoming predominant (4). In another study of 64 patients with a $t(14 ; 18)$ translocation, one patient changed from a follicular small cleaved cell to a diffuse large cell lymphoma that had an additional chromosome 7 . A second patient acquired a $t(1 ; 1)(q 23 ; q 24)$ translocation with the progression of a follicular small cleaved cell lymphoma to a follicular large cell lymphoma (34). More recently, a patient 
was reported to develop Burkitt's lymphoma $15 \mathrm{yr}$ after diagnosis of follicular large cell lymphoma (36).

The study of neoplasms with the sequential acquisition of genetic abnormalities provides insight into the genetic events controlling their behavior and histology. There are a wide variety of secondary genetic changes that can potentially alter the behavior of neoplasms, and consistent patterns of these are now being described in some tumors $(37,38)$. Identifying these changes and understanding how they function to alter cell behavior may lead to more effective antitumor therapies.

\section{Acknowledgments}

The authors wish to thank Drs. Leroy Hood, Stanley Korsmeyer, Philip Leder and Takis Papas for providing probes used in this study. We also acknowledge the expert technical assistance of Ms. Patricia Ennis and thank Dr. Christopher Y. Thomas, IV for assistance in DNA sequencing.

This work was supported in part by National Cancer Institute grant 1 R29 CA-46723-01 (to Dr. Williams). Dr. Williams is the recipient of an American Cancer Society Clinical Oncology Career Development Award.

\section{References}

1. Hubbard, S. M., B. A. Chabner, V. T. DeVita, R. Simon, C. W. Berard, R. B. Jones, A. J. Garvin, G. P. Canellos, C. K. Osborne and R. C. Young. 1982. Histologic progression in non-Hodgkin's lymphoma. Blood. 59:258-264.

2. Oviatt, D. L., J. B. Cousar, R. D. Collins, J. M. Flexner, and R. S. Stein. 1984. Malignant lymphomas of follicular center cell origin in humans. Cancer (Phila.). 53:1109-1114.

3. Woda, B. A., and D. M. Knowles. 1979. Nodular lymphocytic lymphoma eventuating into diffuse histiocytic lymphoma. Cancer (Phila.). 43:303-307.

4. Yunis, J. J., G. Frizzera, M. M. Oken, J. McKenna, A. Theologides, and M. Arnesen. 1987. Multiple recurrent genomic defects in follicular lymphoma. A possible model for cancer. N. Engl. J. Med. 316:79-84.

5. Siegelman, M. H., M. L. Cleary, R. Warnke, and J. Sklar. 1985. Frequent biclonality and Ig gene alterations among B cell lymphomas that show multiple histologic forms. J. Exp. Med. 161:850-863.

6. Showe, L. C., and C. M. Croce. 1987. The role of chromosomal translocations in B- and T-cell neoplasia. Annu. Rev. Immunol. 5:253-77.

7. Sklar, J. L., L. M. Weiss, and M. L. Cleary. 1987. Diagnostic molecular biology of non-Hodgkin's lymphomas. In Malignant Lymphoma. C. W. Berard, R. F. Dorfman, and N. Kaufman, editors. Williams \& Wilkins, Baltimore, MD. 204-224.

8. Yunis, J. J., M. M. Oken, M. E. Kaplan, K. M. Ensrud, R. R. Howe, and A. Theologides. 1982. Distinctive chromosomal abnormalities in histologic subtypes of non-Hodgkin's Lymphoma. $N$. Engl. J. Med. 307:1231-1236.

9. Tsujimoto, Y., L. R. Finger, J. Yunis, P. C. Nowell, C. M. Croce. 1984. Cloning of the chromosome breakpoint of neoplastic $B$ cells with the $t(14 ; 18)$ chromosome translocation. Science (Wash. DC). 226:1097-1099.

10. Bakhshi, A., J. P. Jensen, P. Goldman, J. J. Wright, O. W. McBride, A. L. Epstein, and S. J. Korsmeyer. 1985. Cloning the chromosomal breakpoint of $t(14 ; 18)$ human lymphomas: Clustering around $\mathrm{J}_{\mathrm{H}}$ on chromosome 14 and near a transcriptional unit on 18 . Cell. 41:899-906.

11. Weiss, L. M., R. A. Warnke, J. Sklar, M. L. Cleary. 1987. Molecular analysis of the $t(14 ; 18)$ chromosomal translocation in malignant lymphomas. N. Engl. J. Med. 317:1185-1189.
12. Lee M. S., M. B. Blick, S. Pathak, J. M. Trujillo, J. J. Butler, R. L. Katz, P. McLaughlin, F. B. Hagemeister, W. S. Velasquez, A Goodacre, A. Cork, J. U. Gutterman, and F. Cabanillas. 1987. The gene located at chromosome 18 band q21 is rearranged in uncultured diffuse lymphomas as well as follicular lymphomas. Blood. 70:90-95.

13. Aisenberg, A. C., B. M. Wilkes, and J. O. Jacobson. 1988. The bcl-2 gene is rearranged in many diffuse B-cell lymphomas. Blood. 71:969-972.

14. de Jong, D., B. M. H. Voetdijk, G. C. Beverstock, G. J. B. van Ommen, R. Willemze, and P. M. Kluin. 1988. Activation of the c-myc oncogene in a precursor-B-cell blast crisis of follicular lymphoma, presenting as composite lymphoma. N. Engl. J. Med. 318:1373-1378.

15. Hsu, S. M., L. Raine, and H. Fanger. 1981. The use of antiavidin antibody and avidin-biotin-peroxidase complex in immunoperoxidase technics. Am. J. Clin. Pathol. 75:816-821.

16. Southern, E. M. 1975. Detection of specific sequences among DNA fragments separated by gel electrophoresis. J. Mol. Biol. 98:503-517.

17. Reed, K. C., and D. A. Mann. 1985. Rapid transfer of DNA from agarose gels to nylon membranes. Nucleic Acid. Res. 13:72077221.

18. Siminovitch, K. A., A. Bakhshi, P. Goldman, and S. J. Korsmeyer. 1985. A uniform deleting element mediates the loss of $\mathrm{k}$ genes in human B cells. Nature (Lond.). 316:260-262.

19. Kirsch, I. R., C. C. Morton, K. Nakahara, and P. Leder. 1982. Human immunoglobulin heavy chain genes map to a region of translocations in malignant B lymphocytes. Science (Wash. DC). 216:301303.

20. Max, E. E., J. Battey, R. Ney, I. R. Kirsch, and P. Leder. 1982. Duplication and deletion in the human immunoglobulin e genes. Cell. 29:691-699.

21. Feinberg, A. P., and B. Vogelstein. 1984. A technique for radiolabelling DNA restriction endonuclease fragments to high specific activity. Anal. Biochem. 137:266-267.

22. Williams, M. E., D. J. Innes, M. J. Borowitz, M. A. Lovell, S. H. Swerdlow, P. E. Hurtubise, R. K. Brynes, W. C. Chan, G. E. Byrne, C. C. Whitcomb, and C. Y. Thomas. 1987. Immunoglobulin and T cell receptor gene rearrangements in human lymphoma and leukemia. Blood. 69:79-86.

23. Sanger F., S. Niklen, and A. R. Coulson. 1977. DNA sequencing with chain-terminating inhibitors. Proc. Natl. Acad. Sci. USA. 74:5463-5467.

24. Lukes, R. J., and R. D. Collins. 1975. New approaches to the classification of the lymphomata. Br. J. Cancer. 31(Suppl. I):1-28.

25. Lukes, R. J., J. W. Parker, C. R. Taylor, B. H. Tindle, A. D. Cramer, and T. L. Lincoln. 1978. Immunologic approach to nonHodgkin lymphomas and related leukemias. Analysis of the results of multiparameter studies of 425 cases. Semin. Hematol. 15:322-351.

26. Stein, R. S., J. Cousar, J. M. Flexner, S. E. Graber, L. C. McKee, S. Krantz, and R. D. Collins. 1979. Malignant lymphomas of follicular center cell origin in man: III. Prognostic features. Cancer (Phila.). 44:2236-2243.

27. Zajac-Kaye, M., E. P. Gelmann, and D. Levens. 1988. A point mutation in the c-myc locus of a Burkitt lymphoma abolishes binding of a nuclear protein. Science (Wash. DC). 240:1776-1780.

28. Pearson W. R. and D. J. Lipman. 1988. Improved tools for biological sequence comparison. Proc. Natl. Acad. Sci. USA 85:24442448.

29. Pegoraro, L., A. Palumbo, J. Erikson, M. Falda, B. Giovanazzo, B. S. Emanuel, G. Rovera, P. C. Nowell, and C. M. Croce. 1984. A $14 ; 18$ and an $8 ; 14$ chromosome translocation in a cell line derived from an acute B-cell leukemia. Proc. Natl. Acad. Sci. USA 81:71667170.

30. Gauwerky, C. E., J. Hoxie, P. C. Nowell, and C. M. Croce. 1988. Pre-B-cell leukemia with a $t(8 ; 14)$ and a $t(14 ; 18)$ translocation is preceded by follicular lymphoma. Oncogene. 2:431-435.

31. Tsujimoto, Y., and C. M. Croce. 1986. Analysis of the struc- 
ture, transcripts, and protein products of bcl-2, the gene involved in human follicular lymphoma. Proc. Natl. Acad. Sci. USA. 83:52145218.

32. Cleary, M. L., S. D. Smith, and J. Sklar. 1986. Cloning and structural analysis of cDNAs for bcl-2 and a hybrid bcl-2/immunoglobulin transcript resulting from the $t(14 ; 18)$ translocation. Cell. 47:19-28.

33. Ngan, B. Y., Z. Chen-Levy, L. M. Weiss, R. A. Warnke, and M. L. Cleary. 1988. Expression in non-Hodgkin's lymphoma of the bcl-2 protein associated with the $t(14 ; 18)$ chromosomal translocation. N. Engl. J. Med. 318:1638-1644.

34. Armitage, J. O., W. G. Sanger, D. D. Weisenburger, D. S. Harrington, J. Linder, P. J. Bierman, J. M. Vose, and D. T. Purtilo. 1988. Correlation of secondary cytogenetic abnormalities with histo- logic appearance in non-Hodgkin's lymphomas bearing $t(14 ; 18)$ (q32;q21). J. Natl. Cancer Inst. 80:576-580.

35. Mufti, G. J., T. J. Hamblin, D. G. Oscier, S. Johnson. 1983. Common ALL with pre-B-cell features showing $(8 ; 14)$ and $(14 ; 18)$ chromosome translocations. Blood. 62:1142-1146.

36. Sham, R. L., P. Phatak, J. Carignan, J. Janas, and J. P. Olson. 1989. Progression of follicular large cell lymphoma to Burkitt's lymphoma. Cancer (Phila.). 63:700-702.

37. Vogelstein, B., E. R. Fearon, S. R. Hamilton, S. E. Kern, A. C. Preisinger, M. Leppert, Y. Nakamura, R. White, A. M. M. Smits, and J. L. Bos. 1988. Genetic alterations during colorectal-tumor development. N. Engl. J. Med. 319:525-532.

38. Nowell, P. C. 1988. Molecular events in tumor development. N. Engl. J. Med. 319:575-577. 